\title{
Motoneuron firing in amyotrophic lateral sclerosis (ALS)
}

\author{
Mamede de Carvalho ${ }^{1,2}$ *, Andrew Eisen ${ }^{3}$, Charles Krieger ${ }^{4,5}$ and Michael Swash ${ }^{1,2,6}$ \\ 1 Institute of Physiology and Institute of Molecular Medicine, Faculty of Medicine, University of Lisbon, Lisbon, Portugal \\ 2 Department of Neurosciences, Hospital Santa Maria, Faculty of Medicine, University of Lisbon, Lisbon, Portugal \\ ${ }^{3}$ Emeritus Professor of Neurology, University of British Columbia, Vancouver, BC, Canada \\ ${ }^{4}$ Department of Biomedical Physiology and Kinesiology, Simon Fraser University, Burnaby, BC, Canada \\ ${ }^{5}$ Department of Medicine (Neurology), University of British Columbia, Vancouver, BC, Canada \\ ${ }^{6}$ Institute of Neuroscience, Barts and The London School of Medicine, Queen Mary University of London, London, UK
}

\section{Edited by:}

Maria Piotrkiewicz, Nalecz Institute of

Biocybernetics and Biomedical

Engineering, Poland

\section{Reviewed by:}

C. J. Heckman, Northwestern

University, USA

Maria Piotrkiewicz, Nalecz Institute of

Biocybernetics and Biomedical

Engineering, Poland

\section{${ }^{*}$ Correspondence:}

Mamede de Carvalho, Institute of Physiology and Institute of Molecular Medicine, Faculty of Medicine,

University of Lisbon, Avenida

Professor Egas Moniz, Lisbon

1649-029, Portugal

e-mail: mamedemg@mail.telepac.pt
Amyotrophic lateral sclerosis is an inexorably progressive neurodegenerative disorder involving the classical motor system and the frontal effector brain, causing muscular weakness and atrophy, with variable upper motor neuron signs and often an associated fronto-temporal dementia. The physiological disturbance consequent on the motor system degeneration is beginning to be well understood. In this review we describe aspects of the motor cortical, neuronal, and lower motor neuron dysfunction. We show how studies of the changes in the pattern of motor unit firing help delineate the underlying pathophysiological disturbance as the disease progresses. Such studies are beginning to illuminate the underlying disordered pathophysiological processes in the disease, and are important in designing new approaches to therapy and especially for clinical trials.

\section{Keywords: amyotrophic lateral sclerosis, lower motor neuron, motor cortex, motor units firing, upper motor neuron}

\section{INTRODUCTION}

Motor unit recruitment and firing is fundamental to voluntary movement and motor control. Adrian and Bronk (1929) studied motor unit recruitment and firing rates in normal human muscle, using their newly fabricated concentric needle electrode. They noted that "force exerted by a muscle during a voluntary contraction was the result of the concurrent recruitment of motor units and modulation of the rate at which they discharged action potentials." Denny-Brown and Pennybacker (1938), observed that in the process of recruitment of motor units in electromyographic (EMG) recordings the first recruited units were always small units, successively larger units being recruited as force increased. Henneman et al. (1965), confirmed a pattern of orderly recruitment of successively larger motor units, as deduced by studies of action potentials recorded from motor nerves, not muscle, and introduced the concept of the "size principle" (Grimby and Hannerz, 1968, 1981; Duchateau and Enoka, 2011), showing that at lower levels of activation only low-threshold slow-fatiguing motor units are recruited. At higher force requirements motor units fire more rapidly (Denny-Brown and Pennybacker, 1938). The technological limitations imposed by electrode recording characteristics in human EMG recordings during recruitment imply that low threshold units are sampled almost exclusively in EMG recordings (Grimby and Hannerz, 1981). Grimby and Hannerz (1981), also suggested that, during phasic activity, motor units are recruited in a different order than in tonic activity. More recently, Stein et al. (1972), and Milner-Brown et al. (1973), confirmed that motor units were recruited in relation to size.

Studies of motor unit firing have been neglected in categorizing lower motor neuron (LMN) and upper motor neuron (UMN) disorders, and in mixed UMN and LMN disorders, for example amyotrophic lateral sclerosis (ALS; de Carvalho et al., 2012).

\section{UPPER MOTOR NEURON IN AMYOTROPHIC LATERAL SCLEROSIS}

The modulation of spinal motor neuron firing by the brain and spinal pathways via UMNs, especially by the motor cortex, poses a particular problem in motor physiology, and in understanding the clinical effects of lesions in the motor system (Denny-Brown, 1966). ALS is a motor system disease, although extra-motor areas are also involved (van der Graaff et al., 2009). Magnetic resonance imaging (MRI) analysis of regional volumetric changes in ALS patients, particularly voxel-based morphometry (VBM), has indicated that brain atrophy occurs not only in motor areas, but also in non-motor areas, including frontal, temporal, and parietal lobes of both hemispheres (Agosta etal., 2010; Turner and Modo, 2010; Mezzapesa et al., 2013). Thus ALS is a degenerative brain disease, which is not confined to the motor system. Frontotemporal Dementia (FTD), is a well established, disorder having some features similar to ALS (Lillo and Hodges, 2009; Neary and Snowden, 2013), an observation underscored by the discovery of a hexanucleotide repeat expansion in the first intron of the C9ORF72 gene on chromosome 9p21 associated with both ALS and FTD (DeJesus-Hernandez et al., 2011; Renton et al., 2011). In addition, evolutionary and early life developmental concepts as they relate to the clinical deficits in ALS, also support early cortical involvement in ALS (Eisen et al., 2013).

Classic Charcot-type ALS is characterized by a variable combination of upper and LMN deficits. In about $1 \%$ of ALS patients, the UMN component appears in isolation for many years (by 
definition for more than 4 years); this is referred to as primary lateral sclerosis (PLS). In about $10 \%$ of patients there are isolated LMN features, termed progressive muscular atrophy (PMA). Pathological studies reveal that there is corticospinal (CST) tract degeneration in both PLS and PMA (Ince et al., 2003), an observation that led Gowers (1893) to classify PLS, PMA, and ALS as variants of a single clinical entity, later classified by Brain (1962) as Motor Neuron Disease. PLS usually presents insidiously in the sixth decade of life, with a symmetric, slowly progressive spastic paresis, beginning in the lower extremities, that evolves into a tetrapyramidal syndrome with marked pseudobulbar features (Pringle et al., 1992). Most patients with PLS later develop LMN features. Resting state functional MRI changes in patients with PLS resemble those of ALS (Agosta et al., 2014).

\section{SITE OF ONSET OF ALS}

When Charcot (1874) coined the term ALS, he recognized the importance of degeneration of the lateral columns and of cells in the ventral horns of the spinal cord, either occurring together, which he termed deuteropathic change or only involving only the ventral horns, which he termed protopathic. The notion of upper or LMN syndromes was then unknown, although Lockhart Clarke, in London (Turner et al., 2010), had shown that loss of cells in the ventral horns was accompanied by muscular atrophy. No observations were made as to the possible relevance of these observations to causation of ALS. In his Tuesday lectures, Charcot laid stress on "fibrillary twitches" of muscles in ALS as a particular feature of the disease. Gowers (1893), pointed out that ALS seemed to begin focally and then to spread through the motor system. In contemporary studies, the earliest changes in ALS have been studied using transcranial magnetic stimulation (TMS; Vucic et al., 2013; Vucic and Kiernan, 2013), and functional MRI (Foerster et al., 2013; Zhang et al., 2014). Although there remains uncertainty as to whether "sick" corticomotor neurons can induce anterograde death of spinal motoneurons in ALS, or if corticomotoneurons and anterior horn cells degenerate independently, as suggested in PLS or PMA (Eisen and Weber, 2001), the current evidence supports early cortical motor hyperexcitability in ALS. The importance of the degeneration of cortico-motoneuronal cells in the early clinical findings of loss of dexterity in ALS is well recognized. Indeed, a relatively small reduction of these motoneurons will have greater clinical impact than loss of cortical neurons involved in simpler motor functions (Eisen and Weber, 2001).

\section{MOTOR CORTEX (M1) NEURONS IN ALS}

Precise control of fine finger movement is a characteristic of human motor behavior. The motor neuron circuitry, which includes neurons and cells located both in the cerebral cortex and the spinal cord, is controlled by a complex neural network (Jara etal., 2014). This initiates precise movement of the legs, arms, and hands, breathing, and vocalization, all of which become severely compromised in ALS. The cortical motoneurons known as Betz cells in humans are located in layer $\mathrm{V}$ of the motor cortex. They are also referred to as, CST neurons, or corticomotoneurons. These neurons are characterized by: (1) a large pyramidal cell body, (2) a single apical dendrite that extends toward layer I displaying major branching and arborization, especially within layer II/III, (3) numerous basal dendrites arising from the basolateral surface, and (4) a very long axon that projects toward spinal cord targets (Molnar and Cheung, 2006; Ozdinler and Macklis, 2006; Molyneaux et al., 2007).

Corticospinal neurons are distributed over broad regions of the frontal cortex including premotor areas of the frontal lobe (Maier et al., 2002; Lemon and Griffiths, 2005; Lemon, 2010). The corticomotoneurons in the primary motor cortex (M1) are the major source of descending motor commands for voluntary movement (Lemon, 2010; Quallo et al., 2012; Vigneswaran et al., 2013). These originate, in part, from CST neurons in cortical layer V, whose axons descend to the spinal cord. CST neurons are of two general types. In one type, axons terminate in the intermediate zone of the spinal cord, where they contact spinal interneurons. Some of these interneurons make connections with spinal motoneurons and mediate a component of the descending commands for movement (Maier et al., 2002). The axons of the second type of CST neuron terminate in the ventral horn of the spinal cord, where they make monosynaptic connections with spinal motoneurons. These CST neurons are termed cortico-motoneuronal cells, and are thought to have a role in the generation and control of highly skilled movements, including skilled distal movements and the independent use of digits (Muir and Lemon, 1983; Baker et al., 1995). However, spinal motoneurons receive synaptic input from many sources, implying that even direct corticomotoneurons have a variable influence on the muscles they innervate. Single motor tract axons are not a simple "private line" connecting the cells of origin and spinal motoneurons innervating a single muscle, but instead they may exert simultaneous excitatory and inhibitory influences on different groups of spinal interneurons and motoneurons of multiple muscles at widely separated spinal segments (Shinoda et al., 1986, 2006) as part of the requirement for motor control - see Table 1.

When ALS symptoms begin in the upper limb, typically it is the pincer (precision) grip that is initially weak. The resulting "split-hand syndrome" in which there is thenar-hand weakness and wasting (thenar complex and first dorsal interosseous), with relative sparing of the hypothenar hand, is characteristic of ALS (Eisen and Kuwabara, 2012; Menon et al., 2013). TMS studies of the size of the excitatory postsynaptic potential (EPSP) recorded from the first dorsal interosseous muscle (FDI) during different hand tasks demonstrate the largest EPSP when the FDI is used in a pincer grip (Flament et al., 1993). Whereas in normal subjects the cortical:peripheral ratio (motor evoked potential/compound muscle action potential amplitude) is larger for the thenar compared with the hypothenar complex, in keeping with a stronger corticomotoneuronal input to the thenar hand, this ratio is reversed in ALS, indicating selectively reduced corticomotoneuronal input to the thenar complex (Weber et al., 2000). It is possible that increased functional connectivity, determined by resting state functional MRI, in both the sensorimotor and frontotemporal systems in ALS may reflect a compensatory process in relation to the structural breakdown of the motor and frontotemporal systems (Agosta et al., 2013; Filippi et al., 2013).

During primate evolution a reduction in the number of synapses between the motor cortex and spinal motoneurons innervating the digits has occurred, with an extension of the 
Table 1 | Some characteristics of descending motor tracts.

(1) The lateral descending motor tract group (Cortical spinal and rubrospinal tracts):

Run mainly in the contralateral lateral funiculus of the spinal cord.

Mainly control distal limb muscles rather than axial and proximal muscles.

Exert stronger excitatory effects on flexor muscles and stronger inhibitory effects on extensor muscles.

Excitatory inputs are mediated monosynaptically and inhibitory inputs disynaptically.

(2) Medial descending motor tract group (Vestibular spinal tract, tectospinal tract, reticulospinal tract).

The medial system is phylogenetically and ontogenetically older than the lateral system.

The tracts in the medial system mainly run in the ventral funiculus. The medial system characteristically steers the body, and integrates limb and body movements as well as developing movement synergisms of individual limbs, involving various parts.

Discrete lesions of the medial system usually produces motor disturbance of the axial and the proximal muscles.

direct neocortical, corticomotoneuronal projections beyond the cervical segments of the spinal cord (Lemon and Griffiths, 2005; Vigneswaran etal., 2013). Magnetic stimulation studies have shown that in humans there are direct monosynaptic connections from the motor cortex to the motoneuron pools of virtually all muscle groups, except those of the extra-ocular muscles and vesical and anal voluntary sphincter muscles, and the abductor muscles of the larynx, which are uniquely less vulnerable in ALS until late in the course of the disease (Eisen and Weber, 2001). Reaching and grasping, actions that are fundamental to prehension and the manipulation of objects and tools in primates are complex coordinated activities that are particularly sensitive to abnormalities in central motor control (Lemon and Griffiths, 2005). For example, in the macaque, corticomotoneuronal cells can be just as active during tool use as during precision grip (Vigneswaran et al., 2013).

In humans and other primates, phylogenetically older, indirect pathways project from the motor cortex onto motoneurons (Lemon and Griffiths, 2004). These pathways include the propriospinal, reticulospinal, and rubrospinal tracts (see Table 1). These phylogenetically, older indirect pathways project to segmental interneurons but their contribution to hand movements remains uncertain (Lawrence and Kuypers, 1965, 1968a,b; Isa et al., 2013).

\section{CORTICOMOTONEURONAL HYPEREXCITABILITY}

Eisen et al. (1992) suggested that corticomotoneuronal hyperexcitability might be a mechanism causing both UMN and LMN degeneration in ALS through glutamate-induced excitotoxicity. Increased plasma glutamate levels were first recognized by Plaitakis and Caroscio (1987). TMS studies have demonstrated that cortical hyperexcitability is an early feature of sporadic and familial ALS, linked to motoneuron degeneration (Vucic and Kiernan,
2013; Vucic et al., 2013). In addition, longitudinal studies in asymptomatic SOD-1 mutation carriers and in the G93A SOD1 mouse model (Browne et al., 2006), revealed that cortical hyperexcitability develops prior to the clinical disease onset (Vucic et al., 2008). Loss of parvalbumin-positive inhibitory interneurons in the motor cortex of ALS patients probably contributes to the development of cortical hyperexcitability (Nihei et al., 1993). In addition, reduced expression of the astrocytic glutamate transporter, excitatory amino acid transporter 2 (EAAT2), has been reported both in the SOD-1 mouse model and in the motor cortex and spinal cord of ALS patients (Philips and Rothstein, 2014).

An increased expression of glutamate receptors permeable to excessive influx of $\mathrm{Na}^{+}$and $\mathrm{Ca}^{2+}$ ions has been reported on motoneurons in ALS, thus increasing susceptibility to glutamate toxicity (Williams et al., 1997). There are several molecular features which may render motoneurons vulnerable to glutamate toxicity in ALS. First, motoneurons preferentially express glutamate receptors, such as the AMPA receptors, which are more permeable to influx of $\mathrm{Ca}^{2+}$ ions (Kawahara et al., 2004), and motoneurons in ALS patients lack the intracellular expression of $\mathrm{Ca}^{2+}$ binding proteins parvalbumin and calbindin $\mathrm{D} 28 \mathrm{k}$, both required to buffer intracellular $\mathrm{Ca}^{2+}$ (Alexianu et al., 1994). Aberrant activity of the inositol 1,4,5-triphosphate receptor type 2 receptor has been reported in ALS resulting in higher intracellular concentrations of $\mathrm{Ca}^{2+}$ within the motor neurons (Choe and Ehrlich, 2006). Ultimately, an influx of $\mathrm{Ca}^{2+}$ ions through the ionotropic glutamate receptors NMDA occurs, resulting in increased intracellular $\mathrm{Ca}^{2+}$ concentration and activation of $\mathrm{Ca}^{2+}$-dependent enzymatic pathways that mediate neuronal death (Choi, 1987; Meldrum and Garthwaite, 1990). Glutamate excitotoxicity may also result in production of free radicals and thereby cause cell death (Bondy and LeBel, 1993; Bondy and Lee, 1993).

\section{CORTICOMOTONEURONAL FIRING}

Motor maps derived using intracortical microstimulation have suggested that the motor cortex consists of a mosaic of individual columns, each controlling a single muscle (Asanuma, 1975). However, multiple columns of cortical motoneurons, distributed relatively widely in the motor cortex innervate single spinal motoneurons (Rathelot and Strick, 2006); and individual CST neurons target multiple LMNs representing both agonist and antagonist muscles (Cheney et al., 1985). As in sensory maps, motor maps consist of clusters of functionally related neurons, but their topographic arrangement is coarser (Schreiner and Winer, 2007). Movements can most easily be evoked by stimulation of the deep layers of the motor cortex (Young et al., 2011). Recovery after a lesion in the motor cortex reflects re-establishment of patterns of neuronal firing and cortical circuitry. Maps of movement categories, and the corresponding firing patterns of individual neurons in the motor cortex can be related to patterns of movement (Melgari et al., 2008; Zartl et al., 2013), a hypothesis first suggested by Hughlings Jackson, and demonstrated by cortical stimulation in the macaque by Ferrier in the 19th century. Penfield and colleagues in Montreal, later showed this to be true also for the human brain. Individual CST neurons generally influence whether facilitatory or inhibitory LMNs innervating groups of muscles - termed the cell's muscle field (Aflalo and Graziano, 2006a). 
Microstimulation studies established the sufficiency of motor cortical activity in directing movement and suggested that semidiscrete subregions control the movement of distinct body parts (Rasmussen and Penfield, 1947; Donoghue and Wise, 1982; Gioanni and Lamarche, 1985). This topographic organization, however, reveals relatively little about the precise operations performed by motor cortical networks (Aflalo and Graziano, 2006b). Studies using longer-duration stimulation in monkeys and mice raise the possibility that the motor cortex may be more accurately subdivided on the basis of their involvement in different categories of behavior - defensive postures or movements of the hand to the mouth are examples (Harrison and Murphy, 2012; Bonazzi et al., 2013; Griffin et al., 2014). Movement tuning is defined by the firing rate of component neurons. It must ultimately arise from the pattern of input that drives a particular neuron to fire. As in other cortical areas, local inhibitory neurons in motor cortex act in concert with excitatory neurons to tune downstream cells. Electrophysiological recordings have found that fast-spiking interneurons in motor cortex contribute to movement tuning by restricting all but the most excited neurons from firing. Inhibitory neurons increase their firing rates throughout movement preparation and execution, so they are probably involved in shaping movements. Dendritic gating, and amplification, may provide additional modulation (Aflalo and Graziano, 2006a). The firing rate of a single motor cortex neuron is coarsely related to the direction of arm movement, but the activity of a population of neurons can be transformed into a vector that governs the speed and direction of arm movement.

In ALS, positron emission tomography studies indicate greater cerebral blood flow during motor activation in the contralateral primary sensorimotor cortex and adjacent ventral premotor and parietal association cortex, lateral premotor cortex, the supplementary motor area, the anterior cingulate cortex, the paracentral lobule and the superior and inferior and inferior parietal cortex (Kew et al., 1993). The enhanced motor activation with more marked involvement of the premotor cortex was later documented by functional resonance magnetic studies (Konrad et al., 2002). This observation probably results from cortical reorganization in response to Betz cell loss (Kew et al., 1993).

\section{LOWER MOTOR NEURON AND MOTOR UNIT RECRUITMENT}

The LMN consists of the spinal or brainstem motoneurons that receive input from the descending CST system, as well as from other descending and local segmental connections, many of them interneuronal or conveying afferent input, together with their axonal connections to the cluster of muscle fibers innervated by each motoneuron. The number of muscles fibers making up a motor unit varies in different muscles, with the smallest number in muscles such as finger intrinsic muscles that are engaged in delicate coordinated movement. They show homogeneous histochemical patterns in each motor unit related to their contraction and relaxation characteristics, broadly classified as type I, Type IIA or type IIB motor units (Burke et al., 1971).

In each muscle, force may be graded by varying the firing rate of the activated motor units. The relation between force and firing rate follows a sigmoid curve, force gradation takes place within the middle steep portion of this curve (Kernell et al., 1999).

\section{MOTONEURONS AND THEIR CONNECTIONS}

The control of movement can be evaluated at several levels of the motor control hierarchy, but it is ultimately the spinal motoneuron that is the "lens" through which all motor circuitry must focus its activity (Miri et al., 2013). In general, afferent sensory, efferent motor and interneuronal inputs will dictate LMN firing and so influence movement.

\section{SPINAL MOTONEURON FIRING}

The conventional view regarding LMN firing is that during maintained low intensity motor activities, spinal motoneurons fire at a rate that in healthy humans is greater than $5-6 \mathrm{~Hz}$, with interspike latencies which are not fixed, but which fluctuate to a limited degree. From extensive work on feline and rat LMNs and modeling studies in humans, it is believed that during motor activity voltage trajectories of mammalian motoneurons, including human LMNs, display predictable changes in firing frequency (Kernell, 1965; Schwindt and Calvin, 1972). Kernell (1965) claimed that LMN firing rates in cat increased linearly with stimulating current until the firing rate reaches approximately $25 \mathrm{~Hz}$ (so called "primary range" firing). With stronger stimulation, firing rate increases linearly in many LMNs, but with a greater slope in the relation of stimulating current and firing frequency (so called, "secondary range" firing; Kernell, 1965). In cat LMNs, secondary range firing can reach rates in excess of $125 \mathrm{~Hz}$ (Kernell, 1965). A major determinant of the firing rate is the change in membrane voltage following the spike, the after-hyperpolarization potential (AHP). This waveform has both a descending component ("the scoop"), and an ascending, gradually depolarizing component ("the ramp"), when the membrane potential rises to spike threshold. Slow motoneurons exhibit AHP half-decay times longer than $20 \mathrm{~ms}$ (Gossen et al., 2003; Button et al., 2006). However, in humans at low-firing rates ("subprimary range") LMN depolarization is driven by the noisy input (Matthews, 1996; Kudina, 1999; Macdonell et al., 2008). Adaptation and steady-state firing in motoneurons are assumed to be governed by summation of AHP conductance, the amount of adaptation and the shape and slopes of the steady-state frequency-to-current relation can be explained by non-linear summation of successive spikes (Baldissera et al., 1978).

Multiple potassium conductances contribute to repolarization and therefore the AHP of the LMN action potential, some with short duration "fast" components mediated by IA (4-amino-pyridine-sensitive) and IK (tetraethylammoniumsensitive) potassium channels. "Medium"-duration components of the AHP are mediated by $\mathrm{Ca}^{2+}$-dependent $\mathrm{K}^{+}$conductances (medium afterhyperpolarization; e.g., apamin-sensitive conductance; Zhang and Krnjevic, 1987; Viana etal., 1993), which are generated by small-conductance calcium-activated potassium channels (Sah and Faber, 2002; Miles et al., 2005; Deardorff et al., 2013). Differences between the AHP in LMNs of different sizes (small and large) and between LMN types (fast, F also called type II; and slow, S, also called type I; there are also fatigue-resistant type IIa and fast-fatigable type IIb MNs) are partially responsible for 
the different firing characteristics of these LMNs. The mediumduration AHP is mediated by the apamin-sensitive, SK channel subunits SK2 and SK3, where SK2 is present in all rat alpha-MNs and SK3 is expressed only in a population of S-type rat MNs with longer duration, larger amplitude AHPs (Deardorff et al., 2013). SK2 and SK3 channels are present in feline LMNs in which the peak of the AHP amplitudes appears to be related to the proportion of SK3 and SK2 channels (Deardorff et al., 2013). These SK2 and SK3 channels are prominently associated with cholinergic Ctype synapses, a potential site of modulation of AHP duration and hence, LMN firing rate (Deardorff et al., 2013). Computer simulations of the voltage trajectories of LMNs have been used to derive similar biophysical properties of cat and human LMNs (Jones and Bawa, 1997). Sites of modulation of LMN firing rate include inputs from CST inputs, muscarinic input from interneurons, monoaminergic projections and others especially afferent projections.

Although there is a limited understanding of the relation between LMN firing and the biochemical properties of LMNs recent studies have begun to identify biochemical profiles of different LMN populations. For instance, the notch protein signaling pathway appears to be relevant for LMN specification. In vertebrates and invertebrates neuronal fate is influenced by this pathway which simplistically includes a receptor termed "notch" and a ligand, often called "delta," where both delta and notch can be transmembrane proteins which influence cell-cell interactions. The notch ligand, delta-like homolog 1 (Dlk1) is expressed more highly by large LMNs, compared to small LMNs and co-relates with the fast firing IIb LMN phenotype both by LMN size and firing frequency (Muller et al., 2014). Although Dlk1 may "promote a fast LMN biophysical signature," the variability in expression of Dlk1 is also consistent with previous views that LMN properties may be distributed continuously within the LMN population (Heckman and Enoka, 2012), perhaps related to the variability in expression of specific biochemical "markers" such as Dlk1. Dlk1 could modify LMN properties by changing the profiles of genes expressed in the Dlk1+ expressing MN population. One of the genes modified by Dlk1 expression is a subunit of the delayed rectifier $\mathrm{K}+$ conductance in LMNs called Kcng4 which may be responsible for some but not all of the changes in firing frequency seen in the type IIb LMNs (Muller et al., 2014).

The properties of LMNs profoundly influence their susceptibility to development of ALS. It has been known from studies in mice over-expressing mutant human SOD1 that fast fatiguing (type IIb) LMNs are much more susceptible to LMN axon loss from muscle targets than type I LMNs (Frey et al., 2000; Pun et al., 2006; Hegedus et al., 2008; Saxena et al., 2013). In longitudinal studies of isometric twitch forces and immunocytochemical assessment of muscle innervation in mouse it has been determined that there is impaired sprouting ability of the larger, fast fatiguing IIb LMNs and that axonal die-back of LMNs precedes a significant decline in LMN number (Kennel et al., 1996; Fischer et al., 2004).

A consequence of the stereotyped voltage trajectories of LMNs is the relatively regular firing pattern of normal LMNs and the belief that some specific impairment of LMN firing might characterize ALS. Previous studies have reported irregular firing in single motor unit potentials (MUPs) in ALS patients
(Piotrkiewicz and Hausmanowa-Petrusewicz, 2013), when other simultaneously recorded MUPs from the same muscle fired regularly. These observations were interpreted as suggesting that disease involvement occurred disproportionately in some LMNs, compared to others. The irregularities of firing are attributed variably to ectopic discharges, two or more sequential firings of a MUP (double discharges or "doublets"), or the blocking of neurotransmission in small axonal branches (Piotrkiewicz and Hausmanowa-Petrusewicz, 2013). The loss of LMNs typically results in an increase in the MUP firing rate with an "incomplete" recruitment pattern during routine EMG recordings. However, there is also often a reduction in the firing rate of MUPs with sustained contractions which has often been labeled as "fatigue" and is poorly understood.

The characterization of changes to LMN excitability in ALS has proved challenging. One approach to defining altered LMN excitability is to employ a technique called "threshold tracking" (Burke et al., 2001), which examines nerve excitability by applying subthreshold current pulses and monitoring voltage responses to track changes in the threshold by which modulation of the underlying ionic conductances can be inferred. This method is described elsewhere and has led to claims that ALS patients have altered $\mathrm{Na}^{+}$and $\mathrm{K}^{+}$conductances depending on the stage of disease (Kanai et al., 2006). Early in ALS, patients may have increased persistent $\mathrm{Na}+$ conductances which could lead to the appearance of fasciculations. Later in the disease, $\mathrm{K}+$ conductances decline (Kanai et al., 2006). However, electrophysiological changes found in ALS patients are not replicated with similar protocols applied to mice over-expressing human mutant SOD indicating differences between ALS and the mouse model (Boerio et al., 2010).

Clinically or electrophysiologically detectable fasciculations are almost universal in ALS, but are not requisite for diagnosis. Fasciculation refers to the spontaneous, intermittent activation of some or all of the muscle fibers of one or more motor unit. Isolated fasciculation potentials, without other neurogenic changes are observed in early affected muscles of ALS patients, before increased "jitter" and denervation signs are observed (de Carvalho and Swash, 2013a). The relatively early onset of fasciculation in ALS has led to the view that it results from MN excitability and is a marker or consequence of the MN dysfunction (Denny-Brown and Pennybacker, 1938; de Carvalho and Swash, 2013b). However, fasciculations are not specific in that they can be recorded in many diseases that affect MNs and are often observed in healthy individuals. There is also evidence that some fasciculations are generated at supraspinal sites (de Carvalho et al., 2000). Specific ion channel conductances that might be impaired in ALS include those related to mAHP duration and have long been believed to be a potential factor modulating LMN firing rate. For instance, in experiments using axotomized MNs, Kuno etal. (1974), found changes in mAHP durations which they postulated might be related to a "trophic" signal associated with the activity of the innervated muscle retrogradely transported to the LMN soma (Czeh et al., 1978) or to increased activation of "C"-type synapses on LMN somata as a compensatory response to LMN de-afferentation (Pullen and Sears, 1983). How LMNs function as part of neuron circuits or as members of a more widely distributed "connectome" is a key issue for future research. 


\section{CORTICOSPINAL INPUT TO MNs}

The differing patterns of corticospinal tract projections in different species may correlate with the susceptibility to LMN dysfunction in some species and not others. The relation between CST projections and LMN dysfunction is discussed above - see Tables 1 and 2.

\section{CHOLINERGIC INPUTS: THE C-TYPE SYNAPSE}

The distinctive C-type synapses on LMNs exhibit presynaptic, pleomorphic vesicles, and a post-synaptic submembranous cisternal structure (Pullen and Sears, 1983; Pullen and Athanasiou, 2009). These synapses comprise $5-8.5 \%$ of the total synaptic content on LMNs and are particularly abundant on soma and proximal dendrities. C-type synapses are associated with muscarinic Ach receptors ( $\mathrm{mAchR}$; 2 ), as well as with $\mathrm{K}$ channels (Kv2.1) and SK channels. They are resistant to de-afferentation and spinal hemisection, suggesting that they represent a specific population of spinal cholinergic interneurons. Zagoraiou et al. (2009) have shown that the sole source of C-type synapses is a small group of spinal interneurons (VOc neurons) that express the transcription factor Pitx2. The somata of these cholinergic neurons are located around the central canal and are particularly associated with innervation of LMNs supplying proximal than distal muscles. These interneurons are associated with locomotion (Zagoraiou et al., 2009). They modulate LMN excitability by regulating the mAHP, presumably through their association with SK channels.
These C-type inputs may be particularly important for our understanding of ALS. Examination of LMNs in a transgenic mouse model of ALS and in patients dying with ALS, have shown an increase in C-terminal coverage of spinal LMN with disease progression (Pullen and Athanasiou, 2009). It has been suggested that this is a compensatory response to loss of descending inputs in ALS. Moreover, it is likely that increased C-terminal input will modify LMN firing properties. The relevance of this adaptive response may explain, in part, the clinical observation as to why there are not more prominent UMN signs in ALS patients, even in the presence of substantial UMN loss (Swash, 2012).

\section{MONOAMINERGIC DESCENDING PATHWAYS}

Reticulospinal projections probably contribute to LMN excitability through monoaminergic pathways, including serotonergic and nor-adrenergic fibers (Heckman and Enoka, 2012). These monoaminergic projections largely synapse with LMN dendrites and their activation results in large, persistent inward currents.

\section{THE DOUBLE DISCHARGE (DOUBLET)}

During the evaluation of patients by concentric needle EMG, MUPs are sometimes seen to fire in groups of two or three. Double discharges are rarely found in normal individuals, although they can observed in some muscles during slow voluntary contractions in trained subjects (Bawa and Calancie, 1983; Kudina and Andreeva, 2013). In healthy subjects, the motoneurons with early excitability recovery are capable of firing double discharges

Table 2 | Some descending and segmental inputs on motor neurons.

\begin{tabular}{|c|c|c|c|c|}
\hline Tract or Input & Origin & Target & Significance & Reference \\
\hline Corticospinal tract & $\begin{array}{l}\text { Widespread cortical } \\
\text { regions - especially } \\
\text { frontal cortex }\end{array}$ & $\begin{array}{l}\text { Direct contact with } \\
\text { dendrites of motor } \\
\text { neurons }\end{array}$ & $\begin{array}{l}\text { Single CST axons project to different motor } \\
\text { neuron pools }\end{array}$ & $\begin{array}{l}\text { Maier et al. (2002), } \\
\text { Lemon and Griffiths (2005), } \\
\text { Lemon (2010) }\end{array}$ \\
\hline Rubrospinal tract & $\begin{array}{l}\text { Magnocellular red } \\
\text { nucleus }\end{array}$ & $\begin{array}{l}\text { Motor neurons of } \\
\text { forelimbs }\end{array}$ & $\begin{array}{l}\text { Significance unknown, possible role in } \\
\text { early motor development }\end{array}$ & $\begin{array}{l}\text { Humphrey et al. (1984), } \\
\text { Cheney et al. (1985) }\end{array}$ \\
\hline $\begin{array}{l}\text { Reticulospinal } \\
\text { tract }\end{array}$ & $\begin{array}{l}\text { Arises from pontine and } \\
\text { medullary reticular } \\
\text { formation }\end{array}$ & $\begin{array}{l}\text { Direct and indirect inputs } \\
\text { to motor neurons }\end{array}$ & $\begin{array}{l}\text { May influence motor behavior especially } \\
\text { after damage to CST. } \\
\text { Regulate tonic motor neurons }\end{array}$ & $\begin{array}{l}\text { Wilson and Yoshida (1969), } \\
\text { Riddle et al. (2009), } \\
\text { Baker (2011) }\end{array}$ \\
\hline Propriospinal tract & Cervical spinal cord & May be indirect & $\begin{array}{l}\text { Reaching and grasp behavior, } \\
\text { may mediate some CST activation }\end{array}$ & Kinoshita etal. (2012) \\
\hline Locus coeruleus & $\begin{array}{l}\text { Fibers arise from locus } \\
\text { coeruleus, but also } \\
\text { adjacent brainstem sites }\end{array}$ & $\begin{array}{l}\text { Widespread projections } \\
\text { in spinal cord including } \\
\text { motor neurons }\end{array}$ & $\begin{array}{l}\text { Important source for adrenergic inputs to } \\
\text { motor neurons, may regulate persistent } \\
\text { inward currents (PIC) }\end{array}$ & $\begin{array}{l}\text { Kuypers (1981), } \\
\text { Lee and Heckman (1998), } \\
\text { Heckman and Enoka (2012) }\end{array}$ \\
\hline Raphe nucleus & Raphe nucleus & Widespread projections & $\begin{array}{l}\text { Likely provide serotonergic input to motor } \\
\text { neurons }\end{array}$ & Kuypers (1981) \\
\hline Voc neurons & $\begin{array}{l}\text { Small group of spinal } \\
\text { interneurons } \\
\text { (transcription factor } \\
\text { Pitx2) }\end{array}$ & $\begin{array}{l}\text { Direct input to motor } \\
\text { neuron soma and } \\
\text { proximal dendrites } \\
(\sim 5 \%)\end{array}$ & $\begin{array}{l}\text { Responsible for cholinergic input to } \\
\text { motoneurons and "C-type" synapses }\end{array}$ & Zagoraiou etal. (2009) \\
\hline $\begin{array}{l}\text { Other interneuron } \\
\text { populations }\end{array}$ & $\begin{array}{l}\text { Other small interneuron } \\
\text { populations (V1-V3) }\end{array}$ & Segmental inputs & Modulation of motor neuron firing & Zagoraiou etal. (2009) \\
\hline
\end{tabular}


with a 5-15 ms interspike interval (Kudina and Alexeeva, 1992). The incidence of double discharges is significantly higher in ALS patients, but doublet interval durations and firing patterns of doubling motor units did not differ between ALS and healthy subjects (Piotrkiewicz et al., 2008). It might represent dysfunction of the LMN pool in ALS (Zalewska et al., 1998). The underlying mechanism should involve delayed depolarization (Weber et al., 2009; Kudina and Andreeva, 2010).

\section{THE PRESYNAPTIC TERMINAL OF THE MOTONEURON}

Most neurodegenerative diseases are characterized by extensive neuronal dysfunction and death within the central nervous system. The functional deficit in ALS has therefore been assumed to follow neuronal death. However, there is a recent literature claiming that neuron pathology in ALS is due to a degenerative process that begins in the presynaptic terminal, the neuromuscular junction, or the distal axon (Fischer et al., 2004), which is described in normal aging (Valdez et al., 2012). This degenerative process may initially lead to dying back of the distal axon ("distal axonopathy"), with relative histological preservation of the neuronal cell body and proximal axon. This "dying back" process causes dysfunction in the longest and largest motor axons first. Subsequently, more proximal portions of the axon become affected. This view is based on neuropathological evaluation of some types of toxin-induced peripheral nerve damage (peripheral neuropathy), in which the small intramuscular nerve branches may be affected initially but more proximal portions of axons are spared. This phenomenon probably results from metabolic changes in distal parts of axons associated with reduced axonal transport.

In ALS patients, and in a rodent model of ALS based on over-expression of mutant human superoxide dismutase (mSOD), derived from familial human ALS, pathological changes consistent with distal axonopathy have been reported. Similar changes have been recognized in human familial mutant SOD1 ALS (Fischer et al., 2004). In addition, changes in neuromuscular transmission, presumptively related to changes in pre-synaptic $\mathrm{Ca}^{2+}$ concentration, or altered calcium channel function have been observed (Appel et al., 2001). In the transgenic mouse model a large proportion of neuromuscular junctions show denervation change at a stage when there are only slight reductions in in the numbers of spinal LMNs or ventral root fibers, as determined by electrophysiological (Kennel et al., 1996), or morphological assessment (Fischer et al., 2004; Parkhouse et al., 2008). Furthermore, there are differences in the susceptibility to degeneration of various synaptic subtypes. Synapses of fast fatigable LMNs are vulnerable to synaptic loss, whereas the synapses of slow LMNs are relatively resistant (Frey et al., 2000; Pun et al., 2006; Hegedus et al., 2008). These progressive changes in specific synapses with progressive disease suggest that synapse-specific mechanisms are important. This view is supported to some degree by the observation that the WldS gene, which protects against axonal injury, modestly prolongs survival in the mSOD mouse (Fischer et al., 2005). Synaptic terminals that are less susceptible to denervation also demonstrate greater ability to generate stimulus-induced synaptic sprouting. This might arise from differences in the regulation of the actin cytoskeleton of the synapse. It is also possible that modulation of presynaptic autoreceptors on LMNs might influence its function. For instance, protein kinase alterations influence LMN neurotransmitter release (Santafe et al., 2006). Collectively, these observations suggest that the physiological properties of motor neurons influence firing and that these firing properties can, in turn, influence motor neuron survival, likely by modulating cell excitability (Saxena et al., 2013).

\section{FUNDAMENTAL CURRENT ISSUES}

There has been long standing interest in the possibility that the ionic, or ligand-gated channels expressed by motor neurons might be associated with vulnerability to dysfunction or death in ALS. Considerable attention has been paid to the role of ligand-gated excitatory amino acid receptors, with regard to excitotoxicity, and this topic has been reviewed extensively. Although the mechanisms that lead to aberrant firing of motor neurons, such as the generation of fasciculations in ALS, are unclear, it is clear that motor neuron action potential generation remains critical even as the disorder progresses. As described above, the AHP and conductances underlying this phase of the action potential are modulated by cholinergic inputs (Heckman and Enoka, 2012), and these synaptic inputs are abnormal in a murine model of ALS (Fischer et al., 2004). Nonetheless, involvement of descending inputs from cortex, or from subcortical structures such as monoaminergic axons from locus coeruleus (noradrenergic), or the median raphe (serotonergic), which facilitate persistent inward currents could underlie hyper-excitability and cell dysfunction, and cell survival. Axonal and presynaptic dysfunction is also relevant to the development of ALS. Furthermore, although it is beyond the scope of this review, it is important to recognize that cell dysfunction is not restricted to motor neurons, since other cells in the vicinity of UMNs or LMNs, such as astrocytes, microglia, or glia in the axon periphery may contribute to the development of ALS.

\section{MOTOR UNIT FIRING IN NEUROLOGICAL DISEASE}

Motor unit recruitment and firing patterns determine the characteristics of individualized muscle and limb functions; this requires organization at cortical, basal ganglia, cerebellar, and spinal level in a complex and interwoven output, based on hardware (connections and pathways) and software (learned patterns and combinations of activities). Much remains to be learned about the mechanisms that determine functional capacity.

The main EMG feature in ALS is the abnormal MUP recruitment derived from LMN loss, in particular we observe a reduced number of recruited motor units and an increased firing rate of the recruited motor units. The recruitment order is probably not much altered in ALS (Milner-Brown et al., 1973), but it has been suggested that the recruitment order can be abnormal in neurogenic atrophy, with motor units generating high-twitch tensions sometimes recruited first (Herdmann et al., 1988). Physiologically, the firing rate of new recruited motor units tend to stabilize when other units are added to the recruitment pattern. Indeed, a slight increase in the firing rate is observed in the initially recruited units, but the primary mechanism for increasing force output is the spatial recruitment of more motor units (Petajan, 1991). When no more motor units can be recruited firing rate is very increased, up to $50 \mathrm{~Hz}$. ALS combines both lower and upper motoneuron involvement in the same segment. The impact of UMN lesion 
on the normal fluctuation of LMN discharge rate (Rosenfalck and Andreassen, 1980) is not well known in ALS, but can disturb dexterity and maximal strength.

\section{MOTOR UNIT ACTIVATION AND ITS MODULATION}

The force generated by voluntary striated muscle contraction is regulated by two main mechanisms: recruitment of motor units and modulation of their firing rate. Both recruitment and firing rate modulation arise in response to a common excitatory drive (De Luca et al., 1982). The upper limit of motor unit recruitment differs between muscles, as well as during increasing force. In some hand muscles most motor units are recruited with muscle force less than $40-80 \%$ maximum, but in biceps brachii and tibialis anterior are recruited up to approximately $90 \%$ maximal voluntary contraction force (Heckman and Enoka, 2012). There are a number of sensory feedback loops that modulate LMN firing rates. The regular discharge of motor units at low rates of firing is modulated by muscle spindle activity, as shown in cat experiments by Burke (1968), and, in human recordings by Hagbarth and Vallbo (1969) and Vallbo (1974). These investigators considered that the spindle discharge reinforced alpha motor neurons activity and was important in sensitizing the motor system to sensory input and therefore in modulating motor activity. Cutaneous afferent input feedback also influences motor unit recruitment (Garnett and Stephens, 1981; Kanda and Desmedt, 1983). After cutaneous stimulation higher threshold units show lower recruitment thresholds, thus altering recruitment order (Kanda and Desmedt, 1983). Low threshold motor unit activity is never entirely regular (Rosenfalck and Andreassen, 1980), especially when a unit is firing very slowly, a feature attributed by Stålberg et al. (1973) to spontaneous fluctuations in the trigger level of the motoneuron membrane, variable presynaptic inflow, and short term irregularity in the neuronal depolarization curve, due to "synaptic noise." In general, motor units in muscles innervated by lumbar roots show a slower and more regular firing pattern than motor units in upper limb muscles (Stålberg et al., 1973). The variability of low threshold motor unit discharge is higher in old than in young adults, a feature consistent with the greater force fluctuation observed at low muscle forces in older people (Tracy et al., 2005), this probably derives from longer AHP associated with aging (Piotrkiewicz et al., 2007). In addition, discharge rate variability decreases with an increase in muscle force. Adding this change in discharge rate variability to a motor unit model dramatically improved the ability of the model to produce simulated force fluctuations that mirrored those observed experimentally (Moritz et al., 2005). Motor units with a low threshold for maintained voluntary activity show longer contraction times, lower twitch tension, greater fatigue resistance, smaller MUP amplitudes and lower axonal conduction velocity than motor units of higher threshold (Grimby and Hannerz, 1968).

In ALS, the reduced number of motor units is the major determinant of fatigue, but several mechanisms are involved (Thomas and Zijdewind, 2006). The impact of fatigue on the recruitment properties of motor units in UMN lesions, LMN lesions, and mixed disorders is incompletely understood (Bigland-Ritchie et al., 1986). In general, motor unit discharge rate is reduced and is more regular during fatigue (Gandevia, 1998). Several authors have reported silencing of motor units during prolonged contractions (Kato et al., 1981; Fallentin et al., 1993). Several explanations have been proposed: motoneuron adaptation to a constant excitatory input (Kernell and Monster, 1982); reflex dis-facilitation by a decline in the group Ia excitatory input from muscle spindle afferents (Macefield et al., 1991); reflex inhibition from group III and IV muscle afferents (Duchateau and Hainaut, 1993) and modulation of AHP (Person and Kudina, 1972). It has been suggested that a reduction in motor unit discharge rate matches the slowing of motor unit contractile speed during fatigue, optimizes force, and prevents energy loss (Marsden et al., 1983). However, such adaptation might not occur in high-threshold motor units (Carpentier et al., 2001), representing intrinsic differences in motoneuron adaptation to peripheral feedback. Diverse properties of proximal and distal muscles and relative differences in type I and type II muscle fiber proportions in a muscle might explain some physiological differences. In proximal muscles, monotonic decline in the recruitment threshold of the motor units and the progressive recruitment of new motor units without change in the recruitment order was observed during submaximal fatiguing contractions (Adam and De Luca, 2003), but in distal muscles low-threshold motor units show either no change or an increase in recruitment threshold, as opposed to high-threshold ones that tended to show a progressively reduced threshold (Carpentier et al., 2001). However, these dissimilarities could result, in part, from different experimental protocols.

Central drive is intensified during a fatigue task, as shown by the observation of additional higher threshold motor unit recruitment during fatigue tests (Bigland-Ritchie et al., 1986; Garland et al., 1994). However, there is a complex mechanism of motoneuron adaptation and feedback influences (Peters and Fuglevand, 1999).

\section{IMPACT OF UPPER MOTOR NEURON AND LOWER MOTOR NEURON LESION ON MU RECRUITMENT}

In patients with UMN lesions, without LMN involvement, motor units fire more slowly than normal, probably dependent on longer AHPs in LMNs in affected segments. This has been described in stroke (Liang et al., 2010; Ivanova et al., 2014). In ALS, the impact of UMN lesion on AHP of LMN is certainly dependent on LMN dysfunction, it has been described a AHP shortening in early stages of muscle involvement, increasing with higher relative force deficit (Piotrkiewicz and Hausmanowa-Petrusewicz, 2011). This could be explained by the increased susceptibility of the fast motor units to degeneration in ALS (Piotrkiewicz and Hausmanowa-Petrusewicz, 2011; Piotrkiewicz et al., 2012). This explains that in ALS firing rates have been reported as higher than normal in strong muscles but slower in weak muscles (Piotrkiewicz and Hausmanowa-Petrusewicz, 2011; Piotrkiewicz et al., 2012). Moreover, in ALS patients is observed a higher variability of the interspike-interval of the firing motor units, this finding is consistent with increased excitability of the LMN in this disease (Piotrkiewicz et al., 2012).

UMN lesion causes a consequent reduction in force (Rosenfalck and Andreassen, 1980), and the normal physiological variability of the motor unit firing rate is reduced (Rosenfalck and Andreassen, 1980; de Carvalho et al., 2012) - Figure 1. In patients with ALS there is a complex interplay of different physiological 


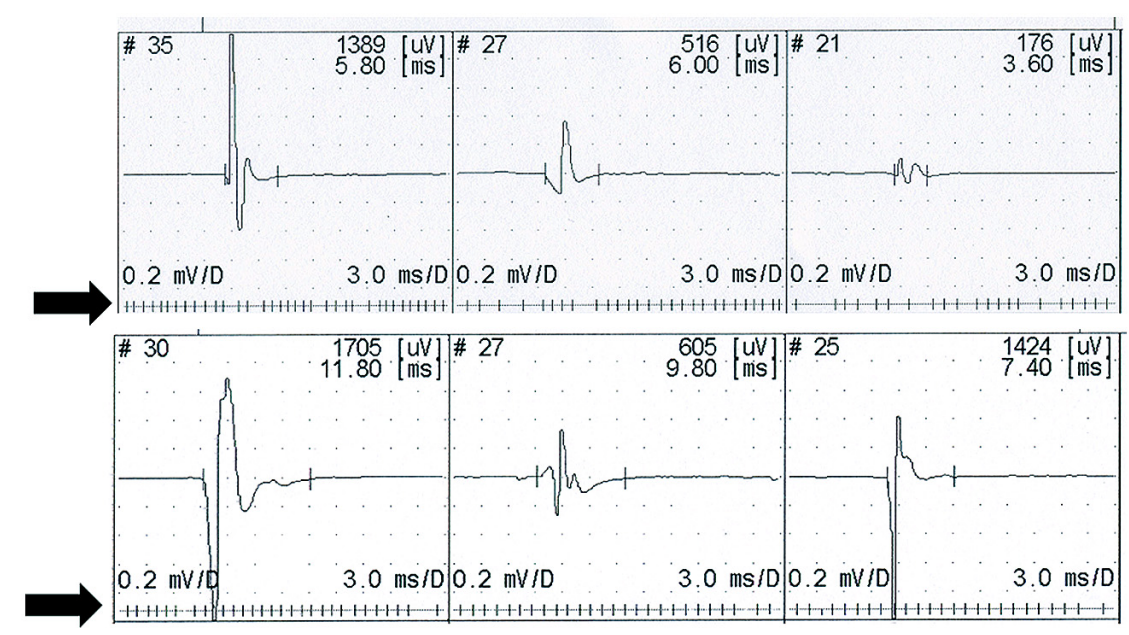

FIGURE 1 | Recruitment of three motor units on slight contraction. The upper recording from a control subject shows physiological slight variability in the firing rate. Lower trace shows a stable firing rate recorded in a patient with upper motor neuron lesion (primary lateral sclerosis). Motor unit potentials are displayed above a raster showing the firing rate.

abnormalities within the spinal motor neurons, presumably reflecting the combination of UMN and LMN features found in this disease (Lawyer and Netsky, 1953; Brownell et al., 1970; Chou, 1995), and possibly the involvement of other systems, such as spinocerebellar afferent pathways (Brownell et al., 1970; Swash et al., 1988). Disruption of interneuronal function in the dorsomedial segment of the ventral horn in the spinal cord (Stephens et al., 2006), dysfunction of Renshaw cells (Raynor and Shefner, 1994; Stephens et al., 2006), and loss of gamma motor neurons (Swash and Fox, 1974; Swash et al., 1986), results in loss of local control mechanisms governing motor unit firing patterns at spinal segmental level (Swash, 2012). In ALS patients with marked clinical signs of UMN lesion, the firing rate behavior approaches that found in clinical conditions only affecting UMNs, in muscle with preserved strength (Rosenfalck and Andreassen, 1980). Reduced modulation of LMN firing by peripheral afferents has been reported in PLS (Floeter et al., 2005).

In UMN lesion with spasticity the $\alpha$-motoneurone is hyperexcitable, so that the membrane potential is closer to threshold than normal, causing facilitation of the effect of voluntary activation on motoneurons, and reduced variability in firing rate. This decreased variability in motor unit firing in UMN syndromes has been explained by activation of persistent inward currents producing stable plateau, which resist changes in response to small inputs (Lee and Heckman, 1998).

In conditions with LMN dysfunction there is a relative failure of the cell's ability to maintain the membrane potential as close to threshold as in pure UMN disorders. Indeed, in patients with LMN dysfunction, as in polyneuropathy and PMA, there is a trend to increased variability in the mean motor unit firing rate as compared with control subjects (de Carvalho et al., 2012).

\section{CONCLUDING REMARKS}

The complex synaptic relationships between the motor cortex, the descending pyramidal and extrapyramidal motor pathways, including the propriospinal system, and the organization of the spinal segmental motor system itself, are progressively destroyed during the course of ALS (Swash, 2012). This process also involves afferent connections at segmental level. This cascade of degeneration determines the clinical phenotype, but the factors leading to the relative severity of involvement, for example, of cortical neurons, UMN pathways, and LMN systems remain unknown. ALS often begins relatively focally, in that weakness may present in localized fashion in one limb before it spreads, in an orderly mode, to become more diffuse (Ravits and La Spada, 2009). However, there is increasingly convincing evidence that ALS has a long pre-clinical phase, before the disease becomes clinically manifest (Eisen et al., 2014). This phase, however, is currently undetectable except insofar as cortical motor physiological studies, using threshold tracking, have revealed early reduction in cortical inhibition, leading to the concept that motor cortex hyperexcitability may be the earliest detectable effect of the disease, perhaps even preceding LMN dysfunction. The critical abnormality in synaptic input to cortical motor system neurons leading to this effect is uncertain.

A major feature of ALS is the inexorable clinical course once the disease has commenced. There are few, if any, incontrovertible reports of survival, or arrest of disease progression. In this respect, ALS seems particularly malignant in its course. Although ALS has been traditionally regarded as a motor degeneration, there are more widespread changes in the brain; for example, there is early degeneration of the spinocerebellar pathways, a spinal afferent system that synapses in Clarke's nucleus in the upper cervical region (Swash et al., 1988). Furthermore, involvement of frontal and prefrontal cortex and its connections is a major feature manifesting as fronto-temporal dementia. This is an evident clinical feature affecting more than half of people with ALS. This clinical manifestation can be regarded as functionally part of the effector system of the brain. Posterior brain systems, related to visual, somatic, and auditory sensory functions, and olfaction, and their 
integrating systems in parietal lobes and spinal cord, are spared. The underlying factors conferring resistance of these pathways to the disease, as is the case also for ocular muscles and the ano-vesical sphincter system, are unknown. With regard to the kinetics of the degenerative process in the motor system, therefore, there is much to be learned.

\section{REFERENCES}

Adam, A., and De Luca, C. J. (2003). Recruitment order of motor units in human vastus lateralis muscle is maintained during fatiguing contractions. J. Neurophysiol. 90, 2919-2927. doi: 10.1152/jn.00179.2003

Adrian, E. D., and Bronk, D. W. (1929). The discharge of impulses in motor nerve fibres: Part II. The frequency of discharge in reflex and voluntary contractions. $J$. Physiol. 67, i3-151.

Aflalo, T. N., and Graziano, M. S. (2006a). Partial tuning of motor cortex neurons to final posture in a free-moving paradigm. Proc. Natl. Acad. Sci. U.S.A. 103, 2909-2914. doi: 10.1073/pnas.0511139103

Aflalo, T. N., and Graziano, M. S. (2006b). Possible origins of the complex topographic organization of motor cortex: reduction of a multidimensional space onto a two-dimensional array. J. Neurosci. 26, 6288-6297. doi: 10.1523/JNEUROSCI.0768-06.2006

Agosta, F., Canu, E., Inuggi, A., Chiò, A., Riva, N., Silani, V., et al. (2014). Resting state functional connectivity alterations in primary lateral sclerosis. Neurobiol. Aging 35, 916-925. doi: 10.1016/j.neurobiolaging.2013.09.041

Agosta, F., Canu, E., Valsasina, P., Riva, N., Prelle, A., Comi, G., et al. (2013). Divergent brain network connectivity in amyotrophic lateral sclerosis. Neurobiol. Aging 34, 419-427. doi: 10.1016/j.neurobiolaging.2012.04.015

Agosta, F., Chiò, A., Cosottini, M., De Stefano, N., Falini, A., Mascalchi, M. et al. (2010). The present and the future of neuroimaging in amyotrophic lateral sclerosis. AJNR Am. J. Neuroradiol. 31, 1769-1777. doi: 10.3174/ajnr. A2043

Alexianu, M. E., Ho, B. K., Mohamed, A. H., La Bella, V., Smith, R. G., and Appel, S. H. (1994). The role of calcium-binding proteins in selective motoneuron vulnerability in amyotrophic lateral sclerosis. Ann. Neurol. 36, 846-858. doi: 10.1002/ana.410360608

Appel, S. H., Beers, D., Siklos, L., Engelhardt, J. I., and Mosier, D. R. (2001). Calcium: the Darth Vader of ALS. Amyotroph. Lateral Scler. Other Motor Neuron Disord. 2(Suppl. 1), S47-S54. doi: 10.1080/146608201300 079418

Asanuma, H. (1975). Recent developments in the study of the columnar arrangement of neurons within the motor cortex. Physiol. Rev. 55, 143-156.

Baker, S. N. (2011). The primate reticulospinal tract, hand function and functiona recovery. J. Physiol. 589(Pt 23), 5603-5612.

Baker, S. N., Olivier, E., and Lemon, R. N. (1995). Task-related variation in corticospinal output evoked by transcranial magnetic stimulation in the macaque monkey. J. Physiol. 488(Pt 3), 795-801.

Baldissera, F., Gustafsson, B., and Parmiggiani, F. (1978). Saturating summation of the afterhyperpolarization conductance in spinal motoneurones: a mechanism for 'secondary range' repetitive firing. Brain Res. 146, 69-82. doi: 10.1016/00068993(78)90218-4

Bawa, P., and Calancie, B. (1983). Repetitive doublets in human flexor carpi radialis muscle. J. Physiol. 339, 123-132.

Bigland-Ritchie, B., Cafarelli, E., and Vollestad, N. K. (1986). Fatigue of submaximal static contractions. Acta Physiol. Scand. Suppl. 556, 137-148.

Boerio, D., Kalmar, B., Greensmith, L., and Bostock, H. (2010). Excitability properties of mouse motor axons in the mutant SOD1(G93A) model of amyotrophic lateral sclerosis. Muscle Nerve 41, 774-784. doi: 10.1002/mus. 21579

Bonazzi, L., Viaro, R., Lodi, E., Canto, R., Bonifazzi, C., and Franchi, G. (2013). Complex movement topography and extrinsic space representation in the rat forelimb motor cortex as defined by long-duration intracortical microstimulation. J. Neurosci. 33, 2097-2107. doi: 10.1523/JNEUROSCI.345412.2013

Bondy, S. C., and LeBel, C. P. (1993). The relationship between excitotoxicity and oxidative stress in the central nervous system. Free Radic. Biol. Med. 14, 633-642. doi: 10.1016/0891-5849(93)90144-J

Bondy, S. C., and Lee, D. K. (1993). Oxidative stress induced by glutamate receptor agonists. Brain Res. 610, 229-233. doi: 10.1016/0006-8993(93)91405-H
Brain, W. R. (1962). "Motor neurone disease," in Diseases of the Nervous System (Oxford: Oxford University Press).

Browne, S. E., Yang, L., DiMauro, J. P., Fuller, S. W., Licata, S. C., and Beal, M. F. (2006). Bioenergetic abnormalities in discrete cerebral motor pathways presage spinal cord pathology in the G93A SOD1 mouse model of ALS. Neurobiol. Dis. 22, 599-610. doi: 10.1016/j.nbd.2006.01.001

Brownell, B., Oppenheimer, D. R., and Hughes, J. T. (1970). The central nervous system in motor neurone disease. J. Neurol. Neurosurg. Psychiatry 33, 338-357. doi: 10.1136/jnnp.33.3.338

Burke, D., Kiernan, M., and Bostock, H. (2001). Excitability of human axons. Clin. Neurophysiol. 112, 1575-1585. doi: 10.1016/S1388-2457(01)00595-8

Burke, R. E. (1968). Group Ia synaptic input to fast and slow twitch motor units of cat triceps surae. J. Physiol. 196, 605-630.

Burke, R. E., Levine, D. N., and Zajac, F. E. (1971). Mammalian motor units: physiological-histochemical correlation in three types in cat gastrocnemius. Science 174, 709-712. doi: 10.1126/science.174. 4010.709

Button, D. C., Gardiner, K., Marqueste, T., and Gardiner, P. F. (2006). Frequencycurrent relationships of rat hindlimb alpha-motoneurones. J. Physiol. 573(Pt 3), 663-677. doi: 10.1113/jphysiol.2006.107292

Carpentier, A., Duchateau, J., and Hainaut, K. (2001). Motor unit behaviour and contractile changes during fatigue in the human first dorsal interosseus. J. Physiol. 534(Pt 3), 903-912. doi: 10.1111/j.1469-7793.2001.00903.x

Charcot, J. M. (1874). Leçons Sur Les Maladies Du Systeme Nerveux Faites a La Salpetriere. Paris: Presse Medicale.

Cheney, P. D., Fetz, E. E., and Palmer, S. S. (1985). Patterns of facilitation and suppression of antagonist forelimb muscles from motor cortex sites in the awake monkey. J. Neurophysiol. 53, 805-820.

Choe, C. U., and Ehrlich, B. E. (2006). The inositol 1,4,5-trisphosphate receptor (IP3R) and its regulators: sometimes good and sometimes bad teamwork. Sci. STKE 2006:re15. doi: 10.1126/stke.3632006re15

Choi, D. W. (1987). Ionic dependence of glutamate neurotoxicity. J. Neurosci. 7, 369-379.

Chou, S. M. (1995). "Pathology of motor system disorder," in Motor Neuron Disease: Biology and Management, eds P. N. Leig and M. Swash (London: Springer Verlag), 53-92. doi: 10.1007/978-1-4471-1871-8_4

Czeh, G., Gallego, R., Kudo, N., and Kuno, M. (1978). Evidence for the maintenance of motoneurone properties by muscle activity. J. Physiol. 281, 239-252.

de Carvalho, M., Miranda, P. C., Lourdes Sales Luís, M., and Ducla-Soares, E. (2000). Neurophysiological features of fasciculation potentials evoked by transcranial magnetic stimulation in amyotrophic lateral sclerosis. J. Neurol. 247, 189-194. doi: $10.1007 /$ s004150050561

de Carvalho, M., and Swash, M. (2013a). Fasciculation potentials and earliest changes in motor unit physiology in ALS. J. Neurol. Neurosurg. Psychiatry 84, 963-968. doi: 10.1136/jnnp-2012-304545

de Carvalho, M., and Swash, M. (2013b). Origin of fasciculations in amyotrophic lateral sclerosis and benign fasciculation syndrome. J. Am. Med. Assoc. Neurol. 70, 1562-1565.

de Carvalho, M., Turkman, A., and Swash, M. (2012). Motor unit firing in amyotrophic lateral sclerosis and other upper and lower motor neurone disorders. Clin. Neurophysiol. 123, 2312-2318. doi: 10.1016/j.clinph.2012.04.016

De Luca, C. J., LeFever, R. S., McCue, M. P., and Xenakis, A. P. (1982). Control scheme governing concurrently active human motor units during voluntary contractions. J. Physiol. 329, 129-142.

Deardorff, A. S., Romer, S. H., Deng, Z., Bullinger, K. L., Nardelli, P., Cope, T. C., et al. (2013). Expression of postsynaptic $\mathrm{Ca}^{2+}$-activated $\mathrm{K}^{+}(\mathrm{SK})$ channels at C-bouton synapses in mammalian lumbar-motoneurons. J. Physiol. 591(Pt 4), 875-897. doi: 10.1113/jphysiol.2012.240879

DeJesus-Hernandez, M., Mackenzie, I. R., Boeve, B. F., Boxer, A. L., Baker, M., Rutherford, N. J., et al. (2011). Expanded GGGGCC hexanucleotide repeat in noncoding region of C9ORF72 causes chromosome 9p-linked FTD and ALS. Neuron 72, 245-256. doi: 10.1016/j.neuron.2011.09.011

Denny-Brown, D. (1966). The Cerebral Control of Movement (The Sherrington Lectures). Liverpool: Liverpool University Press.

Denny-Brown, D., and Pennybacker, J. B. (1938). Fibrillation and fasciculation in voluntary muscle. Brain 61, 311-334. doi: 10.1093/brain/61.3.311

Donoghue, J. P., and Wise, S. P. (1982). The motor cortex of the rat: cytoarchitecture and microstimulation mapping. J. Comp. Neurol. 212, 76-88. doi: $10.1002 /$ cne. 902120106 
Duchateau, J., and Enoka, R. M. (2011). Human motor unit recordings: origins and insight into the integrated motor system. Brain Res. 1409, 42-61. doi: 10.1016/j.brainres.2011.06.011

Duchateau, J., and Hainaut, K. (1993). Behaviour of short and long latency reflexes in fatigued human muscles. J. Physiol. 471, 787-799.

Eisen, A., Kiernan, M., Mitsumoto, H., and Swash, M. (2014). Amyotrophic lateral sclerosis: a long preclinical period? J. Neurol. Neurosurg. Psychiatr. doi: 10.1136/jnnp-2013-307135 [Epub ahead of print].

Eisen, A., Kim, S., and Pant, B. (1992). Amyotrophic lateral sclerosis (ALS): a phylogenetic disease of the corticomotoneuron? Muscle Nerve 15, 219-224. doi: $10.1002 /$ mus. 880150215

Eisen, A., and Kuwabara, S. (2012). The split hand syndrome in amyotrophic lateral sclerosis. J. Neurol. Neurosurg. Psychiatry 83, 399-403. doi: 10.1136/jnnp-2011301456

Eisen, A., Turner, M. R., and Lemon, R. (2013). Tools and talk: an evolutionary perspective on the functional deficits associated with amyotrophic lateral sclerosis. Muscle Nerve 49, 469-477. doi: 10.1002/mus.24132

Eisen, A., and Weber, M. (2001). The motor cortex and amyotrophic lateral sclerosis. Muscle Nerve 24, 564-573. doi: 10.1002/mus. 1042

Fallentin, N., Jorgensen, K., and Simonsen, E. B. (1993). Motor unit recruitment during prolonged isometric contractions. Eur. J. Appl. Physiol. Occup. Physiol. 67, 335-341. doi: 10.1007/BF00357632

Filippi, M., Agosta, F., Scola, E., Canu, E., Magnani, G., Marcone, A., et al. (2013). Functional network connectivity in the behavioral variant of frontotemporal dementia. Cortex 49, 2389-2401. doi: 10.1016/j.cortex.2012.09.017

Fischer, L. R., Culver, D. G., Davis, A. A., Tennant, P., Wang, M., Coleman, M., et al. (2005). The WldS gene modestly prolongs survival in the SOD1G93A fALS mouse. Neurobiol. Dis. 19, 293-300. doi: 10.1016/j.nbd.2005.01.008

Fischer, L. R., Culver, D. G., Tennant, P., Davis, A. A., Wang, M., Castellano-Sanchez, A., et al. (2004). Amyotrophic lateral sclerosis is a distal axonopathy: evidence in mice and man. Exp. Neurol. 185, 232-240. doi: 10.1016/j.expneurol.2003.10.004

Flament, D., Goldsmith, P., Buckley, C. J., and Lemon, R. N. (1993). Task dependence of responses in first dorsal interosseous muscle to magnetic brain stimulation in man. J. Physiol. 464, 361-378.

Floeter, M. K., Zhai, P., Saigal, R., Kim, Y., and Statland, J. (2005). Motor neuron firing dysfunction in spastic patients with primary lateral sclerosis. J. Neurophysiol. 94, 919-927. doi: 10.1152/jn.00185.2005

Foerster, B. R., Dwamena, B. A., Petrou, M., Carlos, R. C., Callaghan, B. C., Churchill, C. L., et al. (2013). Diagnostic accuracy of diffusion tensor imaging in amyotrophic lateral sclerosis: a systematic review and individual patient data meta-analysis. Acad. Radiol. 20, 1099-1106. doi: 10.1016/j.acra.2013.03.017

Frey, D., Schneider, C., Xu, L., Borg, J., Spooren, W., and Caroni, P. (2000). Early and selective loss of neuromuscular synapse subtypes with low sprouting competence in motoneuron diseases. J. Neurosci. 20, 2534-2542.

Gandevia, S. C. (1998). Neural control in human muscle fatigue: changes in muscle afferents, motoneurones and motor cortical drive [corrected]. Acta Physiol. Scand 162, 275-283. doi: 10.1046/j.1365-201X.1998.0299f.x

Garland, S. J., Enoka, R. M., Serrano, L. P., and Robinson, G. A. (1994). Behavior of motor units in human biceps brachii during a submaximal fatiguing contraction. J. Appl. Physiol. 76, 2411-2419.

Garnett, R., and Stephens, J. A. (1981). Changes in the recruitment threshold of motor units produced by cutaneous stimulation in man. J. Physiol. 311, 463-473.

Gioanni, Y., and Lamarche, M. (1985). A reappraisal of rat motor cortex organization by intracortical microstimulation. Brain. Res. 344, 49-61. doi: 10.1016/00068993(85)91188-6

Gossen, E. R., Ivanova, T. D., and Garland, S. J. (2003). The time course of the motoneurone afterhyperpolarization is related to motor unit twitch speed in human skeletal muscle. J. Physiol. 552(Pt 2), 657-664. doi: 10.1113/jphysiol.2003.048132

Gowers, W. R. (1893). A Manual of Diseases of the Nervous System. London: Churchill.

Griffin, D. M., Hudson, H. M., Belhaj-Saif, A., and Cheney, P. D. (2014). EMG activation patterns associated with high frequency, long-duration intracortical microstimulation of primary motor cortex. J. Neurosci. 34, 1647-1656. doi 10.1523/JNEUROSCI.3643-13.2014

Grimby, L., and Hannerz, J. (1968). Recruitment order of motor units on voluntary contraction: changes induced by proprioceptive afferent activity. J. Neurol. Neurosurg. Psychiatry 31, 565-573. doi: 10.1136/jnnp.31.6.565
Grimby, L., and Hannerz, J. (1981). "The electrophysiological differentiation of motor units in man," in Clinical Neurophysiology, eds E. Stålberg and R. R.Young (London: Butterworths).

Hagbarth, K. E., and Vallbo, A. B. (1969). Single unit recordings from muscle nerves in human subjects. Acta Physiol. Scand. 76, 321-334. doi: 10.1111/j.17481716.1969.tb04475.x

Harrison, T. C., and Murphy, T. H. (2012). Towards a circuit mechanism for movement tuning in motor cortex. Front. Neural Circuits 6:127. doi: 10.3389/fncir.2012.00127

Heckman, C. J., and Enoka, R. M. (2012). Motor unit. Compr. Physiol. 2, 2629-2682. Hegedus, J., Putman, C. T., Tyreman, N., and Gordon, T. (2008). Preferential motor unit loss in the SOD1 G93A transgenic mouse model of amyotrophic lateral sclerosis. J. Physiol. 586, 3337-3351. doi: 10.1113/jphysiol.2007. 149286

Henneman, E., Somjen, G., and Carpenter, D. O. (1965). Functional significance of cell size in spinal motoneurons. J. Neurophysiol. 28, 560-580.

Herdmann, J., Reiners, K., and Freund, H. J. (1988). Motor unit recruitment order in neuropathic disease. Electromyogr. Clin. Neurophysiol. 28, 53-60.

Humphrey, D. R., Gold, R., and Reed, D. J. (1984). Sizes, laminar and topographic origins of cortical projections to the major divisions of the red nucleus in the monkey. J. Comp. Neurol. 225, 75-94. doi: 10.1002/cne. 902250109

Ince, P. G., Evans, J., Knopp, M., Forster, G., Hamdalla, H. H., Wharton, S. B., etal. (2003). Corticospinal tract degeneration in the progressive muscular atrophy variant of ALS. Neurology 60, 1252-1258. doi: 10.1212/01.WNL.0000058901.75728.4E

Isa, T., Kinoshita, M., and Nishimura, Y. (2013). Role of direct vs. indirect pathways from the motor cortex to spinal motoneurons in the control of hand dexterity. Front. Neurol. 4:191. doi: 10.3389/fneur.2013.00191

Ivanova, T. D., Knorr, S., MacDonell, C. W., Pollock, C. L., and Garland, S. J. (2014). Motoneurone afterhyperpolarisation time-course following stroke. Clin. Neurophysiol. 125, 544-551. doi: 10.1016/j.clinph.2013. 08.017

Jara, J. H., Genç, B., Klessner, J. L., and Ozdinler, P. H. (2014). Retrograde labeling, transduction, and genetic targeting allow cellular analysis of corticospinal motor neurons: implications in health and disease. Front. Neuroanat. 8:16. doi: 10.3389/fnana.2014.00016

Jones, K. E., and Bawa, P. (1997). Computer simulation of the responses of human motoneurons to composite 1A EPSPS: effects of background firing rate. J. Neurophysiol. 77, 405-420.

Kanai, K., Kuwabara, S., Misawa, S., Tamura, N., Ogawara, K., Nakata, M., et al. (2006). Altered axonal excitability properties in amyotrophic lateral sclerosis: impaired potassium channel function related to disease stage. Brain 129(Pt 4), 953-962. doi: 10.1093/brain/awl024

Kanda, K., and Desmedt, J. E. (1983). Cutaneous facilitation of large motor units and motor control of human fingers in precision grip. Adv. Neurol. 39, 253-261.

Kato, M., Murakami, S., Takahashi K., and Hirayama, H. (1981). Motor unit activities during maintained voluntary muscle contraction at constant levels in man. Neurosci. Lett. 25, 149-154. doi: 10.1016/0304-3940(81)90323-2

Kawahara, Y., Ito, K., Sun, H., Aizawa, H., Kanazawa, I., and Kwak, S. (2004). Glutamate receptors: RNA editing and death of motor neurons. Nature 427:801. doi: $10.1038 / 427801 \mathrm{a}$

Kennel, P. F., Finiels, F., Revah, F., and Mallet, J. (1996). Neuromuscular function impairment is not caused by motor neurone loss in FALS mice: an electromyographic study. Neuroreport 7, 1427-1431. doi: 10.1097/00001756199605310-00021

Kernell, D. (1965). Synaptic influence on the repetitive activity elicited in cat lumbosacral motoneurones by long-lasting injected currents. Acta Physiol. Scand. 63 409-410. doi: 10.1111/j.1748-1716.1965.tb04081.x

Kernell, D., Bakels, R., and Copray, J. C. (1999). Discharge properties of motoneurones: how are they matched to the properties and use of their muscle units? J. Physiol. Paris 93, 87-96. doi: 10.1016/S0928-4257(99)80139-9

Kernell, D., and Monster, A. W. (1982). Time course and properties of late adaptation in spinal motoneurones of the cat. Exp. Brain. Res. 46, 191-196. doi: 10.1007/BF00237176

Kew, J. J., Goldstein, L. H., Leigh, P. N., Abrahams, S., Cosgrave, N., Passingham, R. E. et al. (1993). The relationship between abnormalities of cognitive function and cerebral activation in amyotrophic lateral sclerosis. A neuropsychological 
and positron emission tomography study. Brain 116 (Pt 6), 1399-1423. doi: 10.1093/brain/116.6.1399

Kinoshita, M., Matsui, R., Kato, S., Hasegawa, T., Kasahara, H., Isa, K., et al. (2012). Genetic dissection of the circuit for hand dexterity in primates. Nature 487, 235-238. doi: 10.1038/nature11206

Konrad, C., Henningsen, H., Bremer, J., Mock, B., Deppe, M., Buchinger, C., et al. (2002). Pattern of cortical reorganization in amyotrophic lateral sclerosis: a functional magnetic resonance imaging study. Exp. Brain Res. 143, 51-56. doi: 10.1007/s00221-001-0981-9

Kudina, L. P. (1999). Analysis of firing behaviour of human motoneurones within 'subprimary range'. J. Physiol. Paris 93, 115-123. doi: 10.1016/S09284257(99)80142-9

Kudina, L. P., and Alexeeva, N. L. (1992). After-potentials and control of repetitive firing in human motoneurones. Electroencephalogr. Clin. Neurophysiol. 85, 345353. doi: 10.1016/0168-5597(92)90139-3

Kudina, L. P., and Andreeva, R. E. (2010). Repetitive doublet firing of motor units: evidence for plateau potentials in human motoneurones? Exp. Brain Res. 204 79-90. doi: 10.1007/s00221-010-2298-Z

Kudina, L. P., and Andreeva, R. E. (2013). Motoneuron double discharges: only one or two different entities? Front. Cell Neurosci. 7:75. doi: 10.3389/fncel.2013. 00075

Kuno, M., Miyata, Y., and Munoz-Martinez, E. J. (1974). Differential reaction of fast and slow alpha-motoneurones to axotomy. J. Physiol. 240, 725-739.

Kuypers, H. G. J. M. (1981). "Anatomy of the descending pathways," in Handbook of Physiology - The Nervous System II. American Physiological Society, ed J. M. Brookhart and V. B. Mountcastle (Bethesda, MD: American Physiological Society), 597-666.

Lawrence, D. G., and Kuypers, H. G. (1965). Pyramidal and non-pyramidal pathways in monkeys: anatomical and functional correlation. Science 148, 973-975. doi: 10.1126/science.148.3672.973

Lawrence, D. G., and Kuypers, H. G. (1968a). The functional organization of the motor system in the monkey. I. The effects of bilateral pyramidal lesions. Brain 91, 1-14. doi: 10.1093/brain/91.1.1

Lawrence, D. G., and Kuypers, H. G. (1968b). The functional organization of the motor system in the monkey. II. The effects of lesions of the descending brainstem pathways. Brain 91, 15-36. doi: 10.1093/brain/91.1.15

Lawyer, T. Jr., and Netsky, M. G. (1953). Amyotrophic lateral sclerosis. AMA Arch. Neurol. Psychiatry 69, 171-192. doi: 10.1001/archneurpsyc.1953.02320260 029002

Lee, R. H., and Heckman, C. J. (1998). Bistability in spinal motoneurons in vivo: systematic variations in rhythmic firing patterns. J. Neurophysiol. 80, 572-582.

Lemon, R. N. (2010). What drives corticospinal output? F1000 Biol. Rep. 2:51.

Lemon, R. N., and Griffiths, J. (2004). "Comparative anatomy of the motor system: differences in the oraganization of corticospinal control in different speicies," in Clinical Neurophysiology of Motor Neuron Diseases: Handbook of Clinical Neurophysiology, ed. A. Eisen (Amsterdam: Elsevier B.V.), $7-25$.

Lemon, R. N., and Griffiths, J. (2005). Comparing the function of the corticospinal system in different species: organizational differences for motor specialization? Muscle Nerve 32, 261-279. doi: 10.1002/mus.20333

Liang, L.-Y., Jia-Jin, J. C., Yu-Lin, W., Michal, J., Jolanta, M., and Maria, P. (2010). Changes in spinal motoneuron 'fastness' in post-stroke spastic patients. J. Med Biol. Eng. 30, 17-22.

Lillo, P., and Hodges, J. R. (2009). Frontotemporal dementia and motor neurone disease: overlapping clinic-pathological disorders. J. Clin. Neurosci. 16, 11311135. doi: 10.1016/j.jocn.2009.03.005

Macdonell, C. W., Ivanova, T. D., and Garland, S. J. (2008). Afterhyperpolarization time-course and minimal discharge rate in low threshold motor units in humans. Exp. Brain Res. 189, 23-33. doi: 10.1007/s00221-008-1400-2

Macefield, G., Hagbarth, K. E., Gorman, R., Gandevia, S. C., and Burke, D. (1991). Decline in spindle support to alpha-motoneurones during sustained voluntary contractions. J. Physiol. 440, 497-512.

Maier, M. A., Armand, J., Kirkwood, P. A., Yang, H. W., Davis, J. N., and Lemon, R. N. (2002). Differences in the corticospinal projection from primary motor cortex and supplementary motor area to macaque upper limb motoneurons: an anatomical and electrophysiological study. Cereb. Cortex 12, 281-296. doi: $10.1093 /$ cercor/12.3.281
Marsden, C. D., Meadows, J. C., and Merton, P. A. (1983). 'Muscular wisdom' that minimizes fatigue during prolonged effort in man: peak rates of motoneuron discharge and slowing of discharge during fatigue. Adv. Neurol. 39, 169-211.

Matthews, P. B. (1996). Relationship of firing intervals of human motor units to the trajectory of post-spike after-hyperpolarization and synaptic noise. J. Physiol. 492(Pt 2), 597-628.

Meldrum, B., and Garthwaite, J. (1990). Excitatory amino acid neurotoxicity and neurodegenerative disease. Trends Pharmacol. Sci. 11, 379-387. doi: 10.1016/0165-6147(90)90184-A

Melgari, J. M., Pasqualetti, P., Pauri, F., and Rossini, P. M. (2008). Muscles in "concert": study of primary motor cortex upper limb functional topography. PLOS ONE 3:e3069. doi: 10.1371/journal.pone. 0003069

Menon, P., Bae, J. S., Mioshi, E., Kiernan, M. C., and Vucic, S. (2013). Split-hand plus sign in ALS: differential involvement of the flexor pollicis longus and intrinsic hand muscles. Amyotroph. Lateral Scler. Frontotemporal. Degener. 14, 315-318. doi: 10.3109/21678421.2012.734521

Mezzapesa, D. M., D’Errico, E., Tortelli, R., Distaso, E., Cortese, R., Tursi, M., etal. (2013). Cortical thinning and clinical heterogeneity in amyotrophic lateral sclerosis. PLoS ONE 8:e80748. doi: 10.1371/journal.pone. 0080748

Miles, G. B., Dai, Y., and Brownstone, R. M. (2005). Mechanisms underlying the early phase of spike frequency adaptation in mouse spinal motoneurones. J. Physiol. 566(Pt 2), 519-532. doi: 10.1113/jphysiol.2005.086033

Milner-Brown, H. S., Stein, R. B., and Yemm, R. (1973). The orderly recruitment of human motor units during voluntary isometric contractions. J. Physiol. 230, 359-370.

Miri, A., Azim, E., and Jessell, T. M. (2013). Edging toward entelechy in motor control. Neuron 80, 827-834. doi: 10.1016/j.neuron.2013.10.049

Molnar, Z., and Cheung, A. F. (2006). Towards the classification of subpopulations of layer V pyramidal projection neurons. Neurosci. Res. 55, 105-115. doi: 10.1016/j.neures.2006.02.008

Molyneaux, B. J., Arlotta, P., Menezes, J. R., and Macklis, J. D. (2007). Neuronal subtype specification in the cerebral cortex. Nat. Rev. Neurosci. 8, 427-437. doi: $10.1038 / \mathrm{nrn} 2151$

Moritz, C. T., Barry, B. K., Pascoe, M. A., and Enoka, R. M. (2005). Discharge rate variability influences the variation in force fluctuations across the working range of a hand muscle. J. Neurophysiol. 93, 2449-2459. doi: 10.1152/jn. 01122.2004

Muir, R. B., and Lemon, R. N. (1983). Corticospinal neurons with a special role in precision grip. Brain Res. 261, 312-316. doi: 10.1016/0006-8993(83)90635-2

Muller, D., Cherukuri, P., Henningfeld, K., Poh, C. H., Wittler, L., Grote, P., etal. (2014). Dlk1 promotes a fast motor neuron biophysical signature required for peak force execution. Science 343, 1264-1266. doi: 10.1126/science. 1246448

Neary, D., and Snowden, J. (2013). Frontal lobe dementia, motor neuron disease, and clinical and neuropathological criteria. J. Neurol. Neurosurg. Psychiatry 84, 713-714. doi: 10.1136/jnnp-2012-304549

Nihei, K., McKee, A. C., and Kowall, N. W. (1993). Patterns of neuronal degeneration in the motor cortex of amyotrophic lateral sclerosis patients. Acta Neuropathol. 86, 55-64. doi: 10.1007/BF00454899

Ozdinler, P. H., and Macklis, J. D. (2006). IGF-I specifically enhances axon outgrowth of corticospinal motor neurons. Nat. Neurosci. 9, 1371-1381. doi: 10.1038/nn1789

Parkhouse, W. S., Cunningham, L., McFee, I., Miller, J. M., Whitney, D., Pelech, S. L., et al. (2008). Neuromuscular dysfunction in the mutant superoxide dismutase mouse model of amyotrophic lateral sclerosis. Amyotroph. Lateral Scler. 9, 24-34. doi: 10.1080/17482960701725646

Person, R. S., and Kudina, L. P. (1972). Discharge frequency and discharge pattern of human motor units during voluntary contraction of muscle. Electroencephalogr. Clin. Neurophysiol. 32, 471-483. doi: 10.1016/0013-4694(72)90058-2

Petajan, J. H. (1991). AAEM minimonograph \#3: motor unit recruitment. Muscle Nerve 14, 489-502. doi: 10.1002/mus.880140602

Peters, E. J., and Fuglevand, A. J. (1999). Cessation of human motor unit discharge during sustained maximal voluntary contraction. Neurosci. Lett. 274, 66-70. doi: 10.1016/S0304-3940(99)00666-7

Philips, T., and Rothstein, J. D. (2014). Glial cells in amyotrophic lateral sclerosis. Exp. Neurol. 22, S0014-S4886. 
Piotrkiewicz, M., and Hausmanowa-Petrusewicz, I. (2011). Motoneuron afterhyperpolarisation duration in amyotrophic lateral sclerosis. J. Physiol. 589 (pt 11), 2745-2754. doi: 10.1113/jphysiol.2011.204891

Piotrkiewicz, M., and Hausmanowa-Petrusewicz, I. (2013). Amyotrophic lateral sclerosis: a dying motor unit? Front. Aging Neurosci. 5:7. doi: 10.3389/fnagi.2013.00007

Piotrkiewicz, M., Kudina, L., Chen, J.-J. J., and Hausmanowa-Petrusewicz, I. (2012) Assessment of human motoneuron afterhyperpolarization duration in health and disease. Biocybern. Biomed. Eng. 32, 43-61. doi: 10.1016/S0208-5216(12) 70041-4

Piotrkiewicz, M., Kudina, L., Mierzejewska, J., and Hausmanowa-Petrusewicz, I. (2008). Analysis of double discharges in amyotrophic lateral sclerosis. Muscle Nerve, 38, 845-854. doi: 10.1002/mus.20997

Piotrkiewicz, M., Kudina, L., Mierzejewska, J., Jakubiec, M., and HausmanowaPetrusewicz, I. (2007). Age-related change in duration of afterhyperpolarization of human motoneurones. J. Physiol. 585(Pt 2), 483-490. doi: 10.1113/jphysiol.2007.142356

Plaitakis, A., and Caroscio, J. T. (1987). Abnormal glutamate metabolism in amyotrophic lateral sclerosis. Ann. Neurol. 22, 575-579. doi: 10.1002/ana.410220503

Pringle, C. E., Hudson, A. J., Munoz, D. G., Kiernan, J. A., Brown, W. F., and Ebers, G. C. (1992). Primary lateral sclerosis. Clinical features, neuropathology and diagnostic criteria. Brain 115(Pt 2), 495-520. doi: 10.1093/brain/ 115.2.495

Pullen, A. H., and Athanasiou, D. (2009). Increase in presynaptic territory of C-terminals on lumbar motoneurons of G93A SOD1 mice during disease progression. Eur. J. Neurosci. 29, 551-561. doi: 10.1111/j.1460-9568.2008. 06602.x

Pullen, A. H., and Sears, T. A. (1983). Trophism between C-type axon terminals and thoracic motoneurones in the cat. J. Physiol. 337, 373-388.

Pun, S., Santos, A. F., Saxena, S., Xu, L., and Caroni, P. (2006). Selective vulnerability and pruning of phasic motoneuron axons in motoneuron disease alleviated by CNTF. Nat. Neurosci. 9, 408-419. doi: 10.1038/ nn 1653

Quallo, M. M., Kraskov, A., and Lemon, R. N. (2012). The activity of primary motor cortex corticospinal neurons during tool use by macaque monkeys. J. Neurosci 32, 17351-17364. doi: 10.1523/JNEUROSCI.1009-12.2012

Rasmussen, T., and Penfield, W. (1947). Further studies of the sensory and motor cerebral cortex of man. Fed. Proc. 6, 452-460.

Rathelot, J. A., and Strick, P. L. (2006). Muscle representation in the macaque motor cortex: an anatomical perspective. Proc. Natl. Acad. Sci. U.S.A. 103, 8257-8262. doi: 10.1073/pnas.0602933103

Ravits, J. M., and La Spada, A. R. (2009). ALS motor phenotype heterogeneity, focality, and spread: deconstructing motor neuron degeneration. Neurology 73 , 805-811. doi: 10.1212/WNL.0b013e3181b6bbbd

Raynor, E. M., and Shefner, J. M. (1994). Recurrent inhibition is decreased in patients with amyotrophic lateral sclerosis. Neurology 44, 2148-2153. doi 10.1212/WNL.44.11.2148

Renton, A. E., Majounie, E., Waite, A., Simón-Sánchez, J., Rollinson, S., Gibbs, J. R., etal. (2011). A hexanucleotide repeat expansion in C9ORF72 is the cause of chromosome 9p21-linked ALS-FTD. Neuron 72, 257-268. doi: 10.1016/j.neuron.2011.09.010

Riddle, C. N., Edgley, S. A., and Baker, S. N. (2009). Direct and indirect connections with upper limb motoneurons from the primate reticulospinal tract. J. Neurosci. 29, 4993-4999. doi: 10.1523/JNEUROSCI.3720-08.2009

Rosenfalck, A., and Andreassen, S. (1980). Impaired regulation of force and firing pattern of single motor units in patients with spasticity. J. Neurol. Neurosurg. Psychiatry 43, 907-916. doi: 10.1136/jnnp.43.10.907

Sah, P., and Faber, E. S. (2002). Channels underlying neuronal calcium-activated potassium currents. Prog. Neurobiol. 66, 345-353. doi: 10.1016/S03010082(02)00004-7

Santafe, M. M., Lanuza, M. A., Garcia, N., and Tomàs, J. (2006). Muscarinic autoreceptors modulate transmitter release through protein kinase $\mathrm{C}$ and protein kinase A in the rat motor nerve terminal. Eur. J. Neurosci. 23, 2048-2056. doi 10.1111/j.1460-9568.2006.04753.x

Saxena, S., Roselli, F., Singh, K., Leptien, K., Julien, J. P., Gros-Louis, F., et al. (2013). Neuroprotection through excitability and mTOR required in ALS motoneurons to delay disease and extend survival. Neuron 80, 80-96. doi: 10.1016/j.neuron.2013.07.027
Schreiner, C. E., and Winer, J. A. (2007). Auditory cortex mapmaking: principles, projections, and plasticity. Neuron 56, 356-365. doi: 10.1016/j.neuron.2007.10.013

Schwindt, P. C., and Calvin, W. H. (1972). Membrane-potential trajectories between spikes underlying motoneuron firing rates. J. Neurophysiol. 35, 311-325.

Shinoda, Y., Sugiuchi, Y., Izawa, Y., and Hata, Y. (2006). Long descending motor tract axons and their control of neck and axial muscles. Prog. Brain Res. 151, 527-563. doi: 10.1016/S0079-6123(05)51017-3

Shinoda, Y., Yamaguchi, T., and Futami, T. (1986). Multiple axon collaterals of single corticospinal axons in the cat spinal cord. J. Neurophysiol. 55, 425-448.

Stålberg, E., Thiele, B., and Hilton-Brown, P. (1973). Effect of succinylcholine on single motor end-plates in man. Acta Anaesthesiol. Scand. 17, 108-118. doi: 10.1111/j.1399-6576.1973.tb00805.x

Stein, R. B., French, A. S., Mannard, A., and Yemm, R. (1972). New methods for analysing motor function in man and animals. Brain Res. 40, 187-192. doi: 10.1016/0006-8993(72)90126-6

Stephens, B., Guiloff, R. J., Navarrete, R., Newman, P., Nikhar, N., and Lewis, P. (2006). Widespread loss of neuronal populations in the spinal ventral horn in sporadic motor neuron disease. A morphometric study. J. Neurol. Sci. 244, 41-58. doi: 10.1016/j.jns.2005.12.003

Swash, M. (2012). Why are upper motor neuron signs difficult to elicit in amyotrophic lateral sclerosis? J. Neurol. Neurosurg. Psychiatry 83, 659-662. doi: 10.1136/jnnp-2012-302315

Swash, M., and Fox, K. P. (1974). The pathology of the human muscle spindle: effect of denervation. J. Neurol. Sci. 22, 1-24. doi: 10.1016/0022-510X(74)90050-1

Swash, M., Leader, M., Brown, A., and Swettenham, K. W. (1986). Focal loss of anterior horn cells in the cervical cord in motor neuron disease. Brain 109(Pt 5), 939-952. doi: 10.1093/brain/109.5.939

Swash, M., Scholtz, C. L., Vowles, G., and Ingram, D. A. (1988). Selective and asymmetric vulnerability of corticospinal and spinocerebellar tracts in motor neuron disease. J. Neurol. Neurosurg. Psychiatry 51, 785-789. doi: 10.1136/jnnp.51.6.785

Thomas, C. K., and Zijdewind, I. (2006). Fatigue of muscles weakened by death of motoneurons. Muscle Nerve 33, 21-41. doi: 10.1002/mus.20400

Tracy, B. L., Maluf, K. S., Stephenson, J. L., Hunter, S. K., and Enoka, R. M. (2005). Variability of motor unit discharge and force fluctuations across a range of muscle forces in older adults. Muscle Nerve 32, 533-540. doi: 10.1002/mus.20392

Turner, M. R., and Modo, M. (2010). Advances in the application of MRI to amyotrophic lateral sclerosis. Expert Opin. Med. Diagn. 4, 483-496. doi: $10.1517 / 17530059.2010 .536836$

Turner, M. R., Swash, M., and Ebers, G. C. (2010). Lockhart Clarke's contribution to the description of amyotrophic lateral sclerosis. Brain 133, 3470-3479. doi: 10.1093/brain/awq097

Valdez, G., Tapia, J. C., Lichtman, J. W., Fox, M. A., and Sanes, J. R. (2012). Shared resistance to aging and ALS in neuromuscular junctions of specific muscles. PLoS ONE 7:e34640. doi: 10.1371/journal.pone.0034640

Vallbo, A. B. (1974). Human muscle spindle discharge during isometric voluntary contractions. Amplitude relations between spindle frequency and torque. Acta Physiol. Scand. 90, 319-336. doi: 10.1111/j.1748-1716.1974.tb05594.x

van der Graaff, M. M., de Jong, J. M., Baas, F., and de Visser, M. (2009). Upper motor neuron and extra-motor neuron involvement in amyotrophic lateral sclerosis: a clinical and brain imaging review. Neuromuscul. Disord. 19, 53-58. doi: 10.1016/j.nmd.2008.10.002

Viana, F., Bayliss, D. A., and Berger, A. J. (1993). Multiple potassium conductances and their role in action potential repolarization and repetitive firing behavior of neonatal rat hypoglossal motoneurons. J. Neurophysiol. 69, 2150-2163.

Vigneswaran, G., Philipp, R., Lemon, R. N., and Kraskov, A. (2013). M1 corticospinal mirror neurons and their role in movement suppression during action observation. Curr. Biol. 23, 236-243. doi: 10.1016/j.cub.2012.12.006

Vucic, S., and Kiernan, M. C. (2013). Utility of transcranial magnetic stimulation in delineating amyotrophic lateral sclerosis pathophysiology. Handb. Clin. Neurol. 116, 561-575. doi: 10.1016/B978-0-444-53497-2.00045-0

Vucic, S., Nicholson, G. A., and Kiernan, M. C. (2008). Cortical hyperexcitability may precede the onset of familial amyotrophic lateral sclerosis. Brain 131(Pt 6), 1540-1550. doi: 10.1093/brain/awn071

Vucic, S., Ziemann, U., Eisen, A., Hallett, M., and Kiernan, M. C. (2013). Transcranial magnetic stimulation and amyotrophic lateral sclerosis: pathophysiological insights. J. Neurol. Neurosurg. Psychiatry 84, 1161-1170. doi: 10.1136/jnnp-2012-304019 
Weber, M., Eisen, A., Stewart, H., and Hirota, N. (2000). The split hand in ALS has a cortical basis. J. Neurol. Sci. 180, 66-70. doi: 10.1016/S0022-510X(00)00430-5

Weber, M., Ferreira, V., and Eisen, A. (2009). Determinants of double discharges in amyotrophic lateral sclerosis and Kennedy disease. Clin. Neurophysiol. 120, 1971-1977. doi: 10.1016/j.clinph.2009.08.011

Williams, T. L., Day, N. C., Ince, P. G., Kamboj, R. K., and Shaw, P. J. (1997). Calciumpermeable alpha-amino-3-hydroxy-5-methyl-4-isoxazole propionic acid receptors: a molecular determinant of selective vulnerability in amyotrophic lateral sclerosis. Ann. Neurol. 42, 200-207. doi: 10.1002/ana.410420211

Wilson, V. J., and Yoshida, M. (1969). Comparison of effects of stimulation of Deiters' nucleus and medial longitudinal fasciculus on neck, forelimb, and hindlimb motoneurons. J. Neurophysiol. 32, 743-758.

Young, N. A., Vuong, J., Flynn, C., and Teskey, G. C. (2011). Optimal parameters for microstimulation derived forelimb movement thresholds and motor maps in rats and mice. J. Neurosci. Methods 196, 60-69. doi: 10.1016/j.jneumeth.2010.12.028

Zagoraiou, L., Akay, T., Martin, J. F., Brownstone, R. M., Jessell, T. M., and Miles, G. B. (2009). A cluster of cholinergic premotor interneurons modulates mouse locomotor activity. Neuron 64, 645-662. doi: 10.1016/j.neuron.2009.10.017

Zalewska, E., Rowinska-Marcinska, K., and Hausmanowa-Petrusewicz, I. (1998). Shape irregularity of motor unit potentials in some neuromuscular disorders. Muscle Nerve 21, 1181-1187. doi: 10.1002/(SICI)10974598(199809)21:9<1181::AID-MUS9>3.0.CO;2-3

Zartl, M., Kapfer, T., and Muellbacher, W. (2013). Functional topography of cortical thumb movement representations in human primary motor cortex. Brain Topogr. 27, 228-239. doi: 10.1007/s10548-013-0289-7
Zhang, J., Yin, X., Zhao, L., Evans, A. C., Song, L., Xie, B., et al. (2014) Regional alterations in cortical thickness and white matter integrity in amyotrophic lateral sclerosis. J. Neurol. 261, 412-421. doi: 10.1007/s00415-0137215-5

Zhang, L., and Krnjevic, K. (1987). Apamin depresses selectively the afterhyperpolarization of cat spinal motoneurons. Neurosci. Lett. 74, 58-62. doi: 10.1016/0304-3940(87)90051-6

Conflict of Interest Statement: The authors declare that the research was conducted in the absence of any commercial or financial relationships that could be construed as a potential conflict of interest.

Received: 07 May 2014; accepted: 27 August 2014; published online: 22 September 2014.

Citation: de Carvalho M, Eisen A, Krieger C and Swash M (2014) Motoneuron firing in amyotrophic lateral sclerosis (ALS). Front. Hum. Neurosci. 8:719. doi: 10.3389/fnhum.2014.00719

This article was submitted to the journal Frontiers in Human Neuroscience.

Copyright (C) 2014 de Carvalho, Eisen, Krieger and Swash. This is an open-access article distributed under the terms of the Creative Commons Attribution License (CC BY). The use, distribution or reproduction in other forums is permitted, provided the original author(s) or licensor are credited and that the original publication in this journal is cited, in accordance with accepted academic practice. No use, distribution or reproduction is permitted which does not comply with these terms. 